\title{
O AMÁVEL SENHOR DOS LIVROS
}

Elisa Nazarian

Os livros sempre me livraram de vários suicídios. Digo isto como brincadeira, mas nem tanto. Fui uma criança e uma adolescente tímida, e os livros me deram o conforto e a segurança para conseguir me afirmar. Depois de adulta, o "estrago" já estava feito. Os livros têm me alimentado e me acompanhado diária e incansavelmente.

A figura de José Mindlin sempre me fascinou. Acompanhava sua trajetória pela mídia, e achava fantástico ele ser uma figura polivalente, reunindo o industrial de sucesso a uma figura de importância política, ao mesmo tempo em que era um apreciador de teatro, música, artes plásticas e, sobretudo, livros.

Pertencendo eu mesma a uma família de industriais, nunca tinha imaginado ser possível tal fusão. Na minha família ninguém lia, iam ao teatro por lazer e ninguém entendia de artes plásticas. A música era o único terreno onde alguns se aventuravam.

A certa altura, depois de assistir a uma palestra de Mindlin sobre bibliofilia, na Escola de Comunicação e Artes da USP, resolvi me aproximar dele. Passei a cumprimentá-lo sempre que cruzávamos em eventos culturais e aproveitava para dar uma palavrinha. Ele, muito 
gentil, sem ter a mínima ideia de quem eu fosse, tratava-me com grande cordialidade, mas eu achava pouco. Queria que ele me enxergasse de fato, me destacasse. Foi quando, trabalhando em uma grande livraria, comecei a atendê-lo. Adoro indicar livros e, em geral, acerto nas minhas indicações. Mas ele nem sempre se entusiasmava com o que eu propunha. Mesmo assim, conversávamos um pouco.

À época, eu tinha um livro de poesias praticamente pronto e resolvi mostrar para ele. Tive dúvidas de que ele fosse realmente lê-lo, mas foi com isso que abri as portas para uma grande e preciosa amizade. Ele voltou entusiasmado à livraria uma semana depois, se tanto, convidou-me a conhecer a biblioteca e a partir daí passei a conviver com ele e Guita.

Nunca dei grande importância à raridade de um livro. O que me atrai é o texto, o ritmo, o sabor das palavras. Quando comecei a frequentar a casa dos Mindlin, o que mais me fascinou foram os originais e as cartas de Guimarães Rosa a seus tradutores. Li Grande Sertão: Veredas embalando a gravidez do meu segundo filho, o que foi de uma importância enorme, não só para mim, como para o bebê que eu carregava, hoje um homem de 45 anos, fanático pela obra.

Mindlin deixava-me manusear o que eu quisesse livremente, sem ninguém fiscalizando, e me enriqueci demais com isso.

Depois de uns dois meses em que eu frequentava a casa esporadicamente, fui convidada por ele a trabalhar na biblioteca. Pedi um tempo para pensar. Já tinha tido bastante experiência e prazer trabalhando em livrarias no atendimento ao público, mas não conhecia nada de livros raros, editoração, manuscritos, arquivos etc. Nem era algo que me empolgasse. Precisava de mais movimento. Além disto, minha relação com Guita e Mindlin passara a ser muito próxima, de amizade mesmo, haveria quase uma impossibilidade de manter um distanciamento profissional.

Guita e Mindlin acabaram apressando a minha aceitação, dispensando minhas ressalvas. Fui destinada à seção de arquivos, onde uma organização fazia-se mais do que necessária. Entrei totalmente crua. Nunca havia trabalhado nisso, mas sei ser metódica e criteriosa. Acabei me apaixonando.

O primeiro arquivo que organizei foi o de Francisco Assis Barbosa, começando pelas cartas. Uma delícia. Havia uma quantidade enorme, enviadas por inúmeros remetentes, um verdadeiro retrato, sobretudo das décadas de 1940 a 1960, do Rio de Janeiro e, consequentemente, do Brasil. Drummond, Mário de Andrade, Fernando Sabino, Otto Lara Rezende, Lúcio Cardoso, João Etienne estavam entre eles. No exercício de catalogá-las, acabei me empolgando com várias delas, a ponto de se 
transformarem em verdadeiras sessões de leitura coletiva, reunindo a equipe da livraria e, muitas vezes, o próprio Mindlin, que tinha a maior curiosidade em ouvi-las. Aliás, esta era uma qualidade fundamental em José Mindlin, a curiosidade. Ele se mostrava permanentemente aberto a conhecer coisas novas, sem preconceito. Adorava que lhe contassem algo que não soubesse, que lhe dessem algo para experimentar que não conhecesse, que o instigassem com um autor novo, um filme novo, uma exposição de arte inusitada.

Fui com ele a algumas bienais de artes plásticas e a peças de teatro. Era sempre com paixão que ele se propunha a ir a esses lugares; nunca o vi indo por obrigação, com enfado ou descaso. Cumpre ressaltar que quando passei a conviver com os Mindlin, ele já tinha 85 anos, mas mantinha a capacidade de se deslumbrar e de se encantar também com pequenas coisas, como quando nos chamava para ver uma orquídea que tinha acabado de desabrochar em seu jardim, ou quando chegava à biblioteca trazendo barras de torrone ou de chocolate para "suas meninas".

Mindlin não gostava de estar velho e detestava ser tratado, por algumas mulheres, com termos infantis, usados no diminutivo, como “Que gracinha!”. Dizia que a idade não tira o desejo, só tira a possibilidade. Era vaidoso e independente, e costumava ir ao Rio de Janeiro sozinho, de avião, para os encontros na Academia Brasileira de Letras, mesmo quando já estava quase cego. Voltava deliciado quando alguém, que o reconhecia no aeroporto, oferecia-se para acompanhá-lo até o portão de embarque.

Nunca achei que fosse um intelectual, no sentindo estrito do termo. Comentei isto com ele, que ficou surpreso. Mas é que Mindlin não se prendia a cânones rígidos, ia flutuando ao sabor da sua vontade e dos seus interesses.

Sendo um humanista pouco afeito a tecnologias, não mexia em computadores, não entendia seu funcionamento, e gostava de ser introduzido no mundo virtual em doses muito homeopáticas. Com as secretárias eletrônicas, falava como se fossem pessoas, pedindo às "maquininhas" que transmitissem determinado recado à pessoa ausente.

A biblioteca era um local muito agradável, disposta em dois pavimentos nos fundos de um jardim bem cuidado, na própria casa dos Mindlin, atrás de uma jabuticabeira das mais generosas. Guita zelava com carinho por esse jardim, e uma vez me deu dali um vaso cheio de flores-de-maio, que encantam minha varanda até hoje.

Mindlin vinha à biblioteca quase diariamente. Tinha grande prazer em receber os pesquisadores e em sugerir obras para consulta. Seu imenso amor por seus livros incluía a possibilidade de compartilhá-los. 
Ao longo do tempo em que trabalhei em seu acervo, comprou algumas bibliotecas dentre as inúmeras que lhe foram oferecidas. Não comprava nada em língua estrangeira, livros técnicos, nem volumes muito danificados. Quando lhe pediam estimativa sobre o valor de um livro, costumava dizer que um livro vale, acima de tudo, o quanto quiserem pagar por ele, não importando que seja o único exemplar publicado, a data de publicação etc.

Participei do trabalho de garimpagem dessas bibliotecas que comprou. Pegávamos os livros um por um, líamos para ele o nome do autor, o título. Alguns ele descartava de imediato, outros pedia para ver em mãos. Tínhamos o privilégio de poder ficar com os livros descartados e com isso aprendi muito sobre ótimos autores, hoje caídos no esquecimento, como Ribeiro Couto, Octávio de Faria, Álvaro Moreyra. Os que restavam, e não eram reclamados por ninguém em torno, foram destinados a bibliotecas de presídios, escolas, faculdades e de cidades pequenas do interior de São Paulo.

Quando eu estava organizando os arquivos que pertenciam à biblioteca, sempre me deparava com a bagunça em que estava o arquivo pessoal dele. Na verdade, aquilo nem era um arquivo, mas um amontoado confuso e caótico de cartas, matérias de jornal, notas fiscais de marzipã, receitas médicas, fotos etc. Muitas vezes me propus a colocar aquilo em ordem, mas Mindlin menosprezava seu conteúdo e sua importância, até que, depois de muita insistência minha, acabou cedendo.

Levei um bom tempo, anos mesmo, nesse trabalho. Aos poucos, fui descobrindo e organizando os mais de setecentos correspondentes, vários deles com dezenas de cartas, as inúmeras reportagens, os documentos. E Mindlin, também aos poucos, foi se encantando com aquele enorme testemunho da sua própria vida. Passou a gostar de mostrar seu arquivo aos visitantes.

A equipe da biblioteca era composta por três mulheres: eu, Cristina Antunes e Rosana Gonçalves, e um rapaz, Sérgio Pizoli, responsável pela preservação da vasta coleção de arte em papel dos Mindlin. Estando a biblioteca no próprio terreno da casa deles, inúmeras vezes éramos convidados a almoçar com o casal, almoços sempre fartos e deliciosos. Mindlin tinha muito prazer em comer, em especial os doces, e preferia ter convidados em casa a ir a restaurantes. Era muito frequente a presença de várias pessoas à mesa, e de hóspedes na casa, em geral pessoas muito interessantes. Preocupava-se muito com a atenção dada à cozinheira. Quando ia jantar na casa de alguém, fazia questão de, antes de ir embora, se despedir e agradecer a ela, e fazia o mesmo com as visitas em sua casa. Pedia que passassem na cozinha e cumprissem o ritual. 


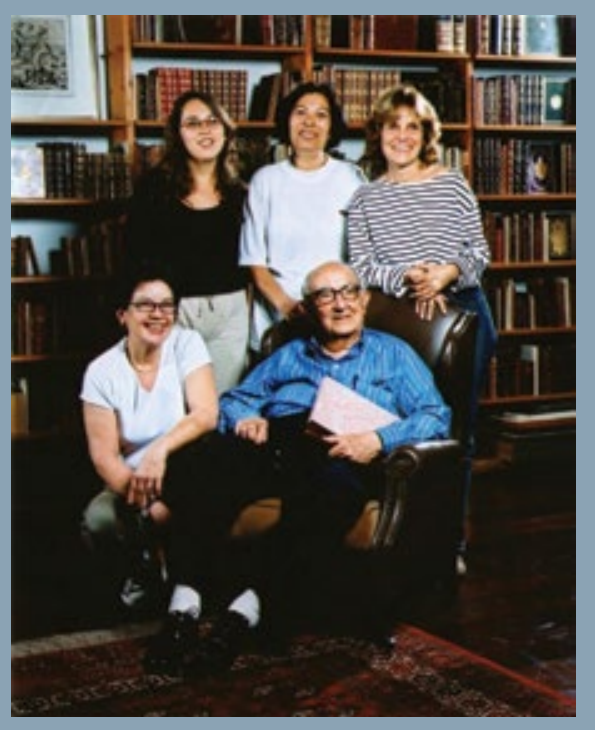

A equipe da biblioteca. Em pé, Rosana Gonçalves, Marivalda e Elisa Nazarian. Sentado está José Mindlin e, ao seu lado, Cristina Antunes.

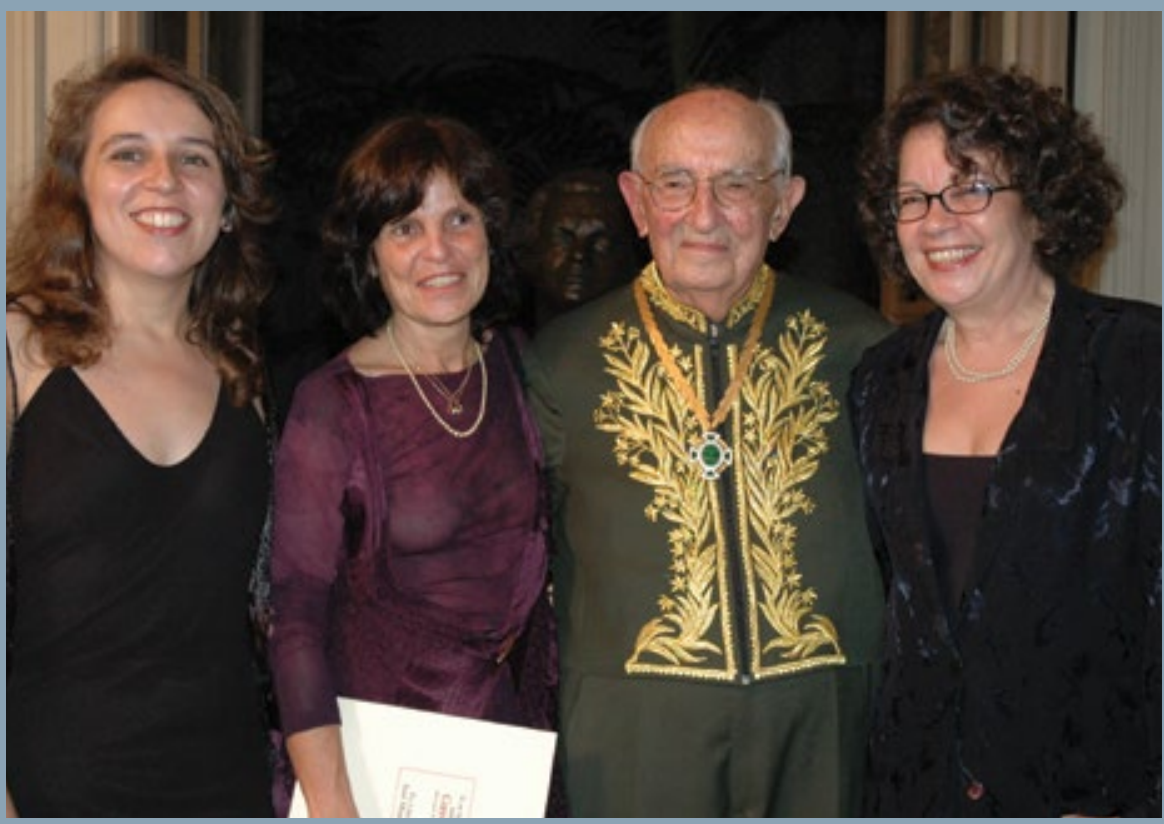

No dia da posse na Academia Brasileira de Letras. Da esquerda para a direita estão Rosana Gonçalves, Elisa Nazarian, José Mindlin e Cristina Antunes. 
Mindlin tratava a todos com extrema delicadeza. Raramente vi, ou soube de ele ter tratado alguém com secura ou rispidez e, quando o fazia, quase sempre se dispunha a rever sua posição, caso alguém que ele respeitasse lhe apresentasse outro ponto de vista. Era, sobretudo, um conciliador e, sendo eu bastante impulsiva, este foi nosso único ponto de atrito em reação a alguém que eu acreditava não merecer o seu crédito.

Embora Guita fosse bem mais reservada, era bastante afetiva, perspicaz e tinha uma boa dose de humor. Certo dia de muito calor, morrendo de sede, fui até a copa da casa buscar um copo d'água. Abri a geladeira em sua presença, peguei uma garrafa - que julguei ser de água - e enchi o copo. Guita quieta. Virei o copo de uma vez e só depois de alguns segundos descobri que aquilo era vodca. Perante o meu espanto, Guita riu e disse: "Eu bem que estava achando estranho você se embebedando a esta hora".

A casa do casal era um retrato explícito de tudo que os dois gostavam. Em um mesmo ambiente conviviam tapetes persas, obras da Tarsila e um móbile do Calder, com um globo espelhado dado por um neto, um quero-quero de madeira trazido por mim.

Na biblioteca tínhamos, as três, nossas funções bem distribuídas, mas o que deu a Rosana um diferencial supremo foi sua capacidade de conseguir achar praticamente tudo o que Mindlin perdia.

Excetuando a biblioteca propriamente dita, de maneira geral, tudo o que vinha dar às mãos de Mindlin perdia-se num buraco negro de difícil acesso. Eu mesma lhe emprestei um livro, que ele nunca leu e que também nunca soube onde foi parar.

Muitas vezes ele se lembrava de algum aspecto do objeto perdido, fosse um documento, uma carta, um livro, uma caixa, mas houve casos em que sua memória foi traiçoeira e o objeto não tinha nada a ver com sua descrição. Mesmo assim, Rosana encontrava-o.

Nos casos mais difíceis, propus que amarrássemos o rabo do diabo, algo pelo qual, a princípio, ele se mostrou totalmente cético. Tratava-se de dar um nó num barbante, numa corda, ou algo parecido, e ameaçar o diabo de ficar eternamente com o rabo amarrado, caso o objeto não fosse encontrado. Depois de obtermos alguns sucessos, o próprio Mindlin abaixou a guarda e, divertido, pedia que recorrêssemos à prática.

Em seus últimos anos, já com a visão muito prejudicada, quase cego, continuava encontrando os livros raros nas prateleiras, sem dificuldade, mas começou a se ressentir dessa limitação. Várias pessoas vinham ler para ele, mas não era a mesma coisa, faltava-lhe autonomia. No início, recorreu a diversas alternativas de lentes especiais, mas a coisa foi se complicando. Também já não conseguia ir ao cinema porque, além do 
problema com a leitura, sua audição limitada não permitia que escutasse o que falavam, o que invalidava o fato de conhecer diversas línguas. Ainda assim, não se permitia o desânimo, o que foi ficando mais difícil a partir do falecimento de Guita. Mindlin não acreditava em vida após a morte, não rezava, nem tinha uma religião formal. Eu, sendo bem mais flexível nas minhas crendices, disse a ele que iria esperá-lo com uma festa, caso fosse a primeira partir. O mínimo que esperava dele, seria o mesmo, caso o primeiro fosse ele. Ele me ouvia e apenas sorria.

Mindlin e Guita tiveram uma participação preciosa na minha vida. Foram meus confidentes, meus amigos, testemunharam vários dos meus momentos difíceis, minhas conquistas, foram ouvidos atentos e solidários. Eram extremamente abertos e ajudaram inúmeras pessoas, inclusive financeiramente.

Meu primeiro livro foi publicado por intermédio de Mindlin. Sem que eu soubesse, ele enviou aquele meu original de poesias a Plinio Martins Filho, não citou meu nome e pediu sua avaliação. Com o resultado favorável em mãos, entregou-me, perguntando se eu aceitaria publicar o livro. Perante a minha negativa, não insistiu. Alguns anos depois, tendo terminado de escrever um romance, procurei pessoalmente Plínio, entreguei-lhe o livro e revelei ser a autora daqueles originais de poesia. O romance foi lindamente publicado pela Ateliê e, na noite de autógrafos, lá estava o casal Mindlin, dando-me mais do que apoio e carinho, conferindo-me legitimidade.

No lançamento do meu segundo livro, também pela Ateliê, pedi a Mindlin que ficasse por lá um tempo, para eu me sentir mais segura. Quando a livraria ficou bem cheia e o lançamento já não corria risco, Mindlin chegou bem perto de mim e disse baixinho, sorrindo: "Posso ir agora?".

\section{SOBRE 0 AUTOR}

Elisa Nazarian é escritora, tradutora e preparadora de texto. Trabalhou em várias livrarias e oito anos junto a José Mindlin. Tem três livros publicados pela editora Ateliê, e o próximo está em fase de elaboração. 


\section{O AMÁVEL SENHOR DOS LIVROS}

RESUMO $\mathrm{O}$ artigo se trata de um relato pessoal da autora quanto à sua relação com José Mindlin, industrial que formou grande coleção de livros raros. Elisa Nazarian conta como conheceu o bibliófilo, passando a trabalhar em sua biblioteca, e como este a ajudou em sua carreira de escritora.

RELATO • BIBLIOTECA • LIVROS • JOSÉ MINDLIN.

\section{THE KIND MR. BOOK}

ABSTRACT This article is a personal account of the author regarding her relationship with José Mindlin, an industrialist who formed a large collection of rare books. Elisa Nazarian tells how she met the bibliophile, then started to work in his library, and how he helped her in her writing career. REPORT • LIBRARY • BOOKS • JOSÉ MINDLIN. 